\title{
Urban Heritage in the Arabian Peninsula, the Experiences of Jeddah and Dubai
}

\author{
Simone Ricca \\ World Heritage Institute of Training and Research for the Asia and the Pacific Region under the auspices of UNESCO \\ (WHITRAP), Shanghai, China \\ Email: s.ricca@whitr.org
}

\begin{abstract}
Saudi Arabia and the United Arab Emirates feature ultra-modern cities with millions of residents that developed in opposition to the physical patterns of traditional historical settlements. In the past years, however, there has been a renewed attention to urban heritage and two metropolises, Jeddah and Dubai, have decided to aim for World Heritage status and to leverage historic city centres as engines of economic development and tools for the reinforcement of national identity. In Dubai, the conservation and reconstruction of historic neighbourhoods gives residents an urban historic depth previously unrecognised, favouring the integration of different ethnic communities while contributing to the tourist development of the Emirate. In Jeddah, the preservation and revitalisation of the historic centre is part of a larger strategy focusing on the reinforcement of the private sector to trigger new urban dynamics building upon its rich heritage. Recent strategies and plans are briefly discussed, underlining the specificities of the Arabian Peninsula context and its complex and evolving relationship with history and heritage. It is argued that the nominations for inscription on the UNESCO World Heritage List have been a catalyser for the definition of new planning and conservation policies integrating urban heritage into urban development strategies.
\end{abstract}

KEYWORDS Jeddah, Dubai, urban heritage, UNESCO World Heritage Convention, Historic Urban Landscape

Received May 22, 2018; accepted June 24, 2018.

\section{Heritage and Modernity in the Arabian Urban Context}

In the past 50 years, the Arabian Peninsula has witnessed an extraordinary urban development that completely modified the landscape of the region (Damluji 2006). Modern cities have been built breaking away from the traditional pattern of local settlements, that used to be relatively small and were characterised by passive temperature control methods and traditional natural ventilation systems. The difference between traditional living practises, that characterised the region until the 1960s, and contemporary urbanised Gulf lifestyle is particularly striking.

International consulting firms and major Anglo-Saxon engineering companies built the modern cities of the Arabian Peninsula. Modernity and an economic approach driven by a strong private and market-oriented vision underpin the contemporary cityscapes of the Arabian Peninsula. The easy access to a seemingly inexhaustible richness, and the progress brought by modern technology, lead to the complete denial of forms, materials and principles deriving from traditional regional architecture. The rupture with traditional building materials and lifestyles accompanied the transition to a hypermodern urban society. Compared with the extraordinary possibilities offered by reinforced concrete and steel, adobe, palm wood and palm leaves were rapidly abandoned. Within few decades, Saudi Arabia and the United Arab Emirates developed ultra-modern metropolises where concentrate not only the largest part of the Arab population but also millions of foreign residents and immigrants.

For some 40 years, Arabian Peninsula countries embraced models and technologies coming from outside, abandoning their own architectural tradition and knowhow and contributing to disconnect younger generations from heritage, history, and national culture. Since the late 1990s however, once the major cities firmly established, a new cultural approach based on the appreciation of 
heritage, and aiming to an idealised 'return' to local values and traditions, has begun to surface (Helmy 2008, 29-36). Unfortunately, in the architectural and urban fields this return was no more physically possible due to the dramatic transformation of Arabian societies and the almost complete destruction of historic buildings and urban centres. The separation between traditional and modern settlements was so radical that the rare heritage buildings that survived the modernisation phase couldn't meet the expectations and the need of 'monumentality' they were now called to play. Hence, many of them 'had' to be improved and beautified because the actual reality of the recent past, characterised by harsh living conditions and widespread poverty, was now perceived as almost unbearable. This denial has often implied the reinterpretation and transformation of traditional local built heritage to become more appealing, clean and monumental. The contrast between this new role and the more prosaic reality of the built vestiges can probably explain the success of 'heritage villages' across the Gulf and of the pastiche orientalist style so frequently used in villas and hotels of the region. The availability of enormous financial resources and empty plots of land, coupled with the search for a national 'identity', favoured a wave of eclectic constructions aiming to evoke, and reconnect with, traditional architecture. International firms, unaware of local culture and constructive techniques, and immigrant workers coming from all over the world, designed and built these mock versions of historic Arabian buildings.

Re-invented heritage did not only aim to 'reassure' the Arab population, but permitted also to project into the past the contemporary image of wealth and power of modern Arabian States, underlining the differences of status and class between the descendants of the original inhabitants of the Peninsula and the millions of foreign immigrants now living in the region. In the Arabian context, however, also the economic and financial implications of heritage-related real estate projects should not be underestimated. Urban heritage, whether reconstructed or original, real or fake, has been co-opted as a significant economic resource by both political leaders and major private entrepreneurs. Large urban development plans, aiming to (re)create 'historic city centres' have been implemented in Qatar, Sharjah, and elsewhere.

Among the many cities of the Arabian Peninsula, two metropolises have decided in the past years to follow a different path and to apply for inscription on the UNESCO World Heritage List (WHL): Jeddah in Saudi Arabia and Dubai in the United Arab Emirates (UAE).
Notwithstanding the differences, these two cities, located on the shores of the Red Sea and of the Persian Gulf respectively, present a series of relevant similarities that deserve to be underlined. Both cities are:

- Traditional merchant centres with a long-lasting tradition of international exchanges and trade;

- Maritime cities with historic ports that favoured/originated their development as multi-cultural settlements with specific architectural traditions resulting from the fusion of local constructive know-hows with ideas and traditions coming from afar along the maritime commercial routes;

- Cities with a strong identity and a degree of independence from central powers.

The Historical City of Jeddah, the Gate of Makkah became a Word Heritage Site in June 2014, while the nomination of Khor Dubai, a traditional merchants' harbour, highly controversial, has not met with the same success and has been withdrawn by the UAE at the $42^{\text {nd }}$ Session of the World Heritage Committee in Manama on July 2018.

This recent quest for international recognition (Saudi Arabia inscribed its first property on the WHL in 2008, the United Arab Emirates in 2011) epitomises the new role 'heritage' has acquired in the region. The nomination of two large metropolises characterised by their 'modernity', however, marks a further step in this process and poses new challenges both to local authorities and planners, and to the international heritage community.

Since 2010, Dubai and Jeddah have designed innovative strategic plans that aim to integrate their urban and architectural heritage into a rapidly evolving urban environment. In a somehow parallel and independent process, these Arabian Peninsula metropolises have developed urban strategies that echo the approach proposed by the 2011 UNESCO Historic Urban Landscape Recommendation. Building upon the principles of contemporary urban conservation, these plans seem to address the past and the future at the same time and to recognise and position the historic city as a resource for the future, as recommended by Francesco Bandarin and Ron van Oers (2012).

The presentation of these two cities in the following pages underlines the specificity of the cultural, urban and geographical context of the Arabian Peninsula, but points also out common issues and trends that can be relevant for other 'modern' metropolises. While most 'new megalopolises' have not yet been able to define operational principles able to ensure urban conservation models respecting the values, traditions and environments of different cultural contexts, Jeddah and Dubai have strived 


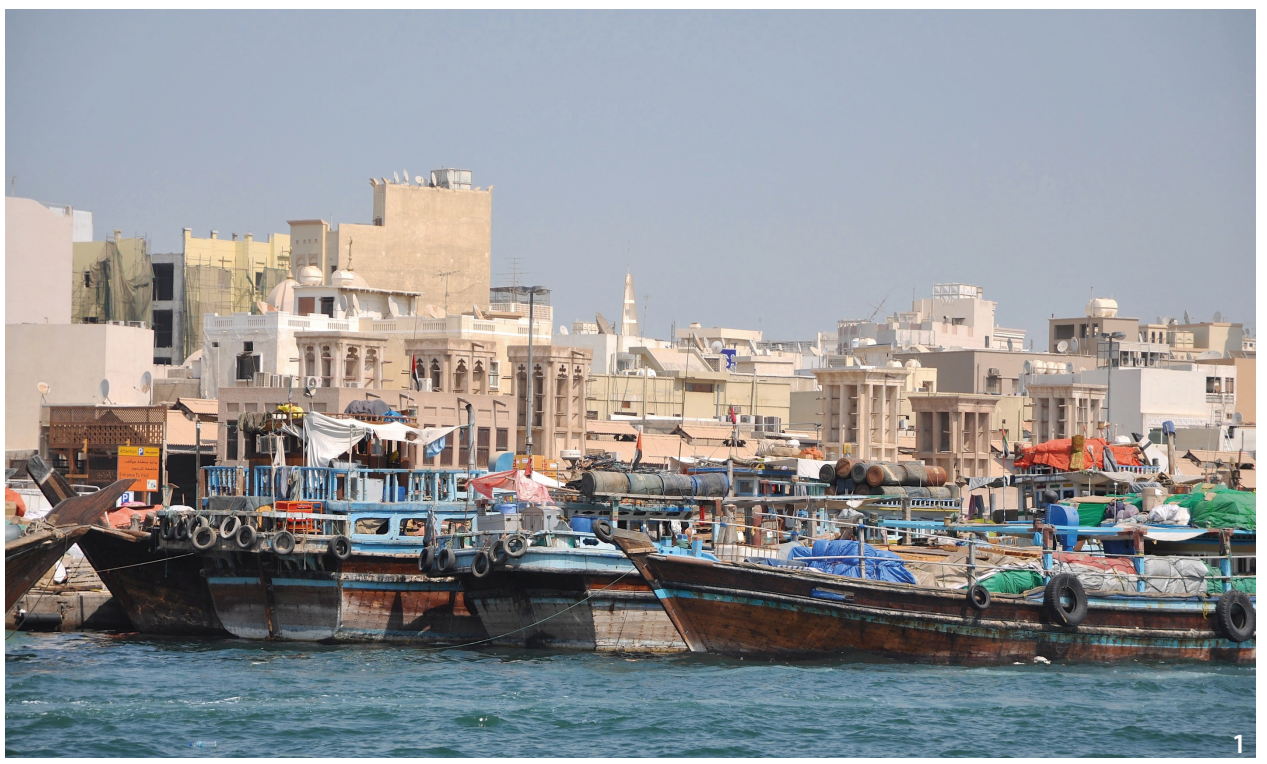

Figure 1 Wooden dhows in Dubai Creek, 2013 (Source: F. Cristofoli).

to redefine their future building upon their multiple and fragile urban heritage.

\section{Dubai}

\section{Urban History and Evolution}

The modern city of Dubai counts some 2.4 million inhabitants and extends over tens of kilometres along the Gulf shores. The original nucleus of the city is now just a small sector of a large metropolis that has shifted its focus from the banks of Dubai Creek to the Gulf seafront.

'Dubai is widely perceived as the quintessential postmodern city characterised by its impressive and distinctive skyline crowned by the highest building in the world, Burj Khalifa.' (Assi 2015, 66) Yet, the modern metropolis originates from a small merchants' settlement that developed along Dubai Creek in the second half of the $19^{\text {th }}$ century. The physical and intangible vestiges of this early phase are still visible, and traditional markets and wooden boats are still found in the heart of the modern metropolis. Wooden boat-making, gold, silk and spice trade, covered souks, traditional palaces and wind-catchers constitute a unique urban environment enhanced by the presence of the 14-km long Dubai Creek (Figure 1).

Mentioned in Europe the first time in 1580 by the Venetian merchant Gasparo Balbi as a small fishing village active in pearling, Dubai remained a minor settlement until the beginning of the $19^{\text {th }}$ century. The origins of the modern city of Dubai are rooted in the tribal culture and political history of the region. In 1833, a subsection of the Bani Yas tribe seceded from Abu Dhabi and moved to form an independent sheikhdom in Dubai, where the presence of the Creek offered favourable conditions. Dubai maintained its independence and by the late 1870 s emerged as the principal port of the region (Pacione 2005).

In the early $20^{\text {th }}$ century, Dubai was an embryonic citystate with a population of some 10,000 people. The town grew along the Creek and consisted of three distinct quarters: Deira, the largest, lying on the north side of the creek, with a mixed population of Arabs, Persians, and other nationalities; Shindagha, bounded on one side by the sea and the other by the creek, was the base of the ruling Arab clan; Bur Dubai, contained about 200 houses, 50 shops, the Faheidi Fort, the principal mosque and the Indian and Bastaki neighbourhoods (Coles and Jackson 2007).

The world recession of 1929 , and the introduction of the cultured pearl, undermined the economy of the region. With the demise of the pearling industry, Dubai placed greater emphasis on trade. In the 1940s, the population of Dubai numbered around 20,000 and by 1955, the urban area just covered $3.2 \mathrm{~km}^{2}$. The majority of inhabitants continued to live in extended families within residential quarters often built in palm frond and organised in clusters for privacy and collective security. The few stone houses belonged either to the Ruler's family or to the families of the leading merchants. During the 1950s, Dubai's prosperity increased with the growth of the gold trade with India that progressively faded during the 1970s with the reduction of demand from the Indian market. The dredging of Dubai Creek in 1958-1959 was the first essential step in laying the foundations for a modern commercial city and produced an immediate increase of the commercial traffic and of the city's wealth. In the 1960s and 1970s, the city began to develop rapidly according to the 1960 Master Plan 


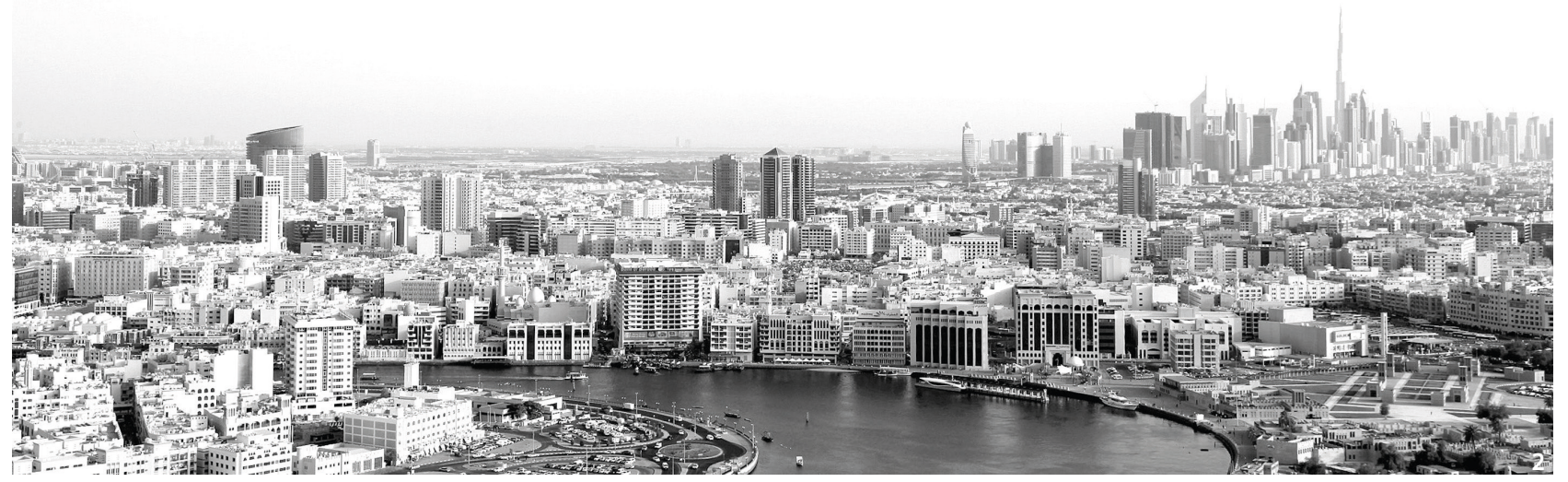

Figure 2 Skyline of modern Dubai, 2015 (Source: S. Kuny/AHD).

designed by the British firm of John Harris. Following the discovery of petroleum offshore in 1966, the development of the oil industry revolutionised the economy and the society of Dubai, enabling the government to undertake major infrastructure and industrial projects like the construction of Port Rashid, the dry docks, and, later the Jebel Ali port and industrial area (Pacione 2005).

The discovery of oil also led to a massive influx of foreign workers, mainly Indians and Pakistanis, and between 1968 and 1975 the city's population grew by over 300\%. In 1971 the United Arab Emirates (UAE) came into existence and Dubai rapidly emerged as the principal economic and urban centre of the region. In the 1970s, Dubai population used to double every six or seven years. A large area extending towards Jebel Ali (Jumeirah) was designated for residential use along Sheikh Zayed Road, a growth corridor that later characterised the 'New Dubai' and emerged as the commercial and financial centre of the modern metropolis (Heard-Bey 2004). Dubai specific land ownership rules-stating that within a settlement any plot of land that has been occupied by a family for a lengthy period belongs to the inhabitant, while elsewhere land property is at the disposal of the Ruler-allowed considerable central control over the city's development pattern and made it possible (Wirth 1988).

The 1980s and 1990s were a period of rapid expansion, and by 2004 the city covered an area of $605 \mathrm{~km}^{2}$. The Dubai Urban Area Strategic Plan 1993-2012 was drawn to guide the economic and physical development of the city into the $21^{\text {st }}$ century. In the $2000 \mathrm{~s}$, the objectives proposed by the Strategic Plan were already overcome in a phase of incredibly fast urban and economic development. Within few years, Dubai became a global metropolis, a leading tourist destination, a major real estate world player, the seat of the largest multinational companies, the city of the highest building of the world, of the largest commercial malls, and of the longest driverless metro (Figure 2). A series of mega-projects were launched and partially realised within few years, while the very territory of the Emirate was modified by the creation of large artificial islands that have significantly increased the seafront of the city. The global financial crisis of 2008 led to a reconsideration of the development strategy and to a greater concern for the sustainability of the urban growth and development plans. The awarding of Dubai as seat of the 2020 World Expo, however, has put in motion yet another phase of urban development materialised by the recent creation of a new gigantic airport close to the Abu Dhabi border.

The transformation of the city from a small settlement largely made of palm-frond houses into a major world metropolis has taken place in less than fifty years. Dubai has become the very symbol of the Gulf cities, an ever-changing urban environment where, as the saying goes, 'the only constant is change' (Wheeler and Thuysbaert 2005).

\section{Urban Heritage and Modernity}

During its growth phase, neither the leadership, nor the population at large, paid much attention to Dubai's architectural heritage. In the 1980s, the expansion of the Ruler's administrative court lead to the partial demolition of Bastakiya neighbourhood, while at the beginning of the 1990s most of Shindagha palaces were razed in view of a new development plan. Thus, two of the most important historic sectors of the city, where stood the first and the most refined examples of coral stone architecture and wind-towers, were partially razed to pave the way for 'modernity' and 'development'. The destruction of traditional houses in the city, however also had an opposite effect, 

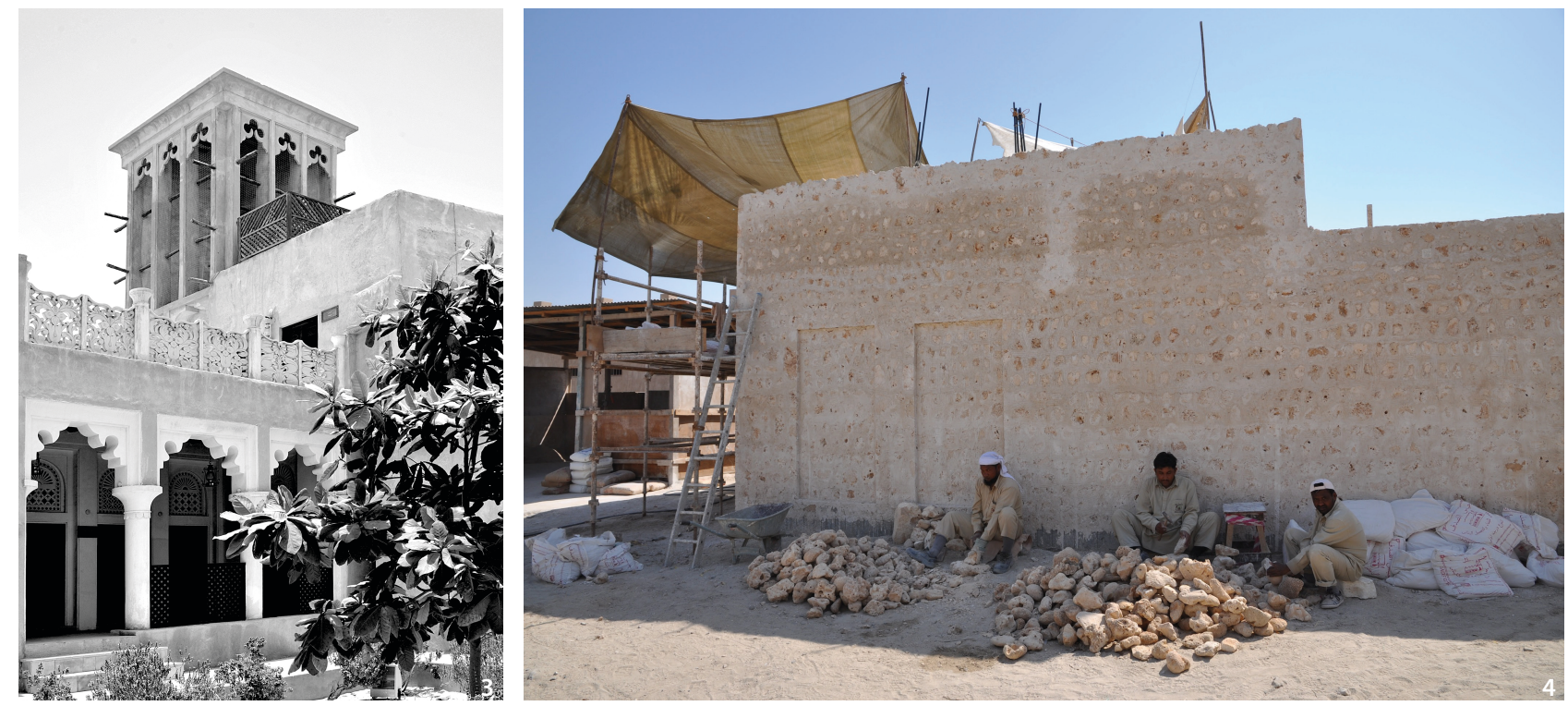

Figure 3 Restored Al-Faheidi House, 2013 (Source: F. Cristofoli).

Figure 4 Reconstructing the neighbourhood of Shindagha, 2013 (Source: F. Cristofoli).

and contributed to developing a new attention to traditional architectural and urban heritage in the city elite.

Since 1995, Dubai Municipality carried out the revitalisation of Bastakiya, to revive the historic fabric and to restore its beautiful courthouses. Within five years, a full restoration program for 62 residential units was implemented (Olroyd-Robinson 2006; Assi and Bukhash 2011). The surviving part of this restored neighbourhood represents today one of the most important architectural, historical, and cultural asset of Dubai (Figure 3). The traditional souks of Deira and Bur Dubai, with their animated covered alleys and shops still bearing the names of ancient merchants' families from the Emirates, Persia, India, and beyond, have also been restored and continue to play an important role in the city's economic life.

More recently, the neighbourhood of Shindagha too has attracted public and governmental attention to convert the site into a showcase of Emirati heritage (Boussaa 2014). In this case, after the demolition of the original buildings, Dubai Municipality has launched an ambitious plan for its scientific reconstruction. By 1999, the original mosques were renovated and in 2017 the reconstruction of the houses of the neighbourhood is almost completed.

In the past 30 years, modern Dubai has grown in a spectacular way, with an accelerated pace of development rarely seen at the global scale. Yet, while most Gulf cities have completely lost their original nucleus, replaced by high-rise buildings and modern facilities, Dubai has been able to preserve a substantial part of its original historic centre because urban growth progressively shifted from the creek to the sandy shores of the Gulf, reducing real estate pressure on the historic centre. This development pattern, coupled with a renewed attention to heritage, made the municipal policies for the preservation, restoration and reconstruction of Dubai historic neighbourhoods possible.

\section{Conservation and Reconstruction in Dubai: An Assessment}

Introduction

Since the 1990s, Dubai urban elites began to question the systematic adoption of Western architectural and urban principles-often unsuitable for the climatic and social environment of the Gulf-and started looking back at historic settlements for alternative solutions and answers. Within a large-scale urban conservation plan, historic areas and buildings began to be re-used for cultural activities. Supported by the Ruler, and by the wealth of the citystate, Dubai has developed a network of small museums and cultural venues, and restored a small but coherent historic neighbourhood-al-Faheidi neighbourhood, formerly known as Bastakiya-and two historic souks. Since the end of the 1990s, efforts concentrated in the neighbourhood of Shindagha, painstakingly reconstructed in what is likely the largest urban reconstruction project of the region, that aims at presenting Dubai residents and tourists a vivid showcase of Dubai's cultural past (Figure 4).

Since 2012, Dubai Municipality has strived to inscribe the historic centre and the creek on the UNESCO World Heritage List (United Arab Emirates 2012). This ambitious challenge, identified as a priority project by the city's 
authorities, has permitted to review and update the city's conservation strategy, and to develop a more contemporary and dynamic vision of 'heritage' capable to include not only the historic buildings, but also the economic dynamics related to traditional trade, the urban waterway (Dubai Creek) and the urban morphology. This pursuit of international recognition answers to both cultural and economic considerations as Dubai's urban heritage is called to play a double role: on the one side to prove Emiratis that they have an historic depth upon which it is possible to plan a more locally-rooted future; on the other side to provide the millions of tourists that visit modern Dubai a new 'attraction' capable to prolong their stay in the city.

\section{A Gulf 'Historic' City}

In an ultra-modern, highly efficient, and very wealthy city like Dubai, urban conservation follows different principles and faces very different challenges than in traditional Middle Eastern historic cities. Dubai Municipality urban management mechanisms are highly developed, and the city offers first-class services to the city residents: electricity, water, parking, garbage collection, traffic control and all other aspects of modern life are dealt with in a highly professional manner. The Municipality provides the residents-whether citizens or foreigners-with all the facilities required to carry out their daily life and to develop their activities. This effectiveness, however, is intimately connected to the perception of the city as a 'service-provider' catering for its residents, and not as a representative body implementing the decisions of the community. Dubai 'post-modern' metropolis is a city where residents have an easy access to all services, but have no say in the political decision-making process.

Conservation in Dubai has met the favour of the local elites and of the Ruler, but has to confront a very dynamic business environment with access to immense financial resources and used to plan large-scale development projects. These different approaches have resulted in the overlapping of conservation projects and developers' plans where the borders between culture and authentic heritage on the one side, and business and pastiche on the other, are often blurred. The reproduction of traditional architectural details in modern buildings, mechanically copied and often blown out of proportion, has become an abstract stylistic references for the design of the eclectic post-modern architecture of many Dubai resorts (Rab 2010). While, in turn, also the misperceptions produced by the modern imitations of traditional architecture seems to affect some restoration and reconstruction plans. The formal conservation of architectural elements without preserving their technical function (wind-towers), or the reproduction of architectural and urban patterns disconnected from their social and cultural context, risks producing a sterile 'heritage' environment that bears little resemblance to the vibrant life the historic city used to have. The dichotomy between the original houses and neighbourhoods and the restored and reconstructed ones is further underlined by the fact that it is no more possible to re-use these spaces as residential areas. The dramatic evolution of Emirati lifestyle makes these houses no more suitable as residences for the rich urban elites, while the political and identity role they are called to play prevents their re-use as residences for lower social classes and foreign immigrants. In Dubai Municipality's perspective, the former houses of the Ruler's family or of the city's wealthiest merchants 'cannot' be inhabited by less privileged residents, and can only be transformed into cultural venues, museums, galleries, or, in the best case, into temporary residences and boutique hotels for rich tourists.

Yet, the criticism of Dubai's heritage conservation strategy should be nuanced when considering urban heritage in a more contemporary sense. Dubai and its creek still constitute a very lively and active environment where the economic dynamics that permitted the development of the city in the past century continue to be active today. A wide range of products and manufactured goods is traded in the shops of the city that still belong to Arab, Indian and Persian merchants who settled in Dubai since the end of the $19^{\text {th }}$ century. Similarly, in Deira's gold souk-extending over a larger modern sector of the city-tons of gold and jewellery are sold daily, attracting thousands of local and international customers according to a century-old tradition. Dubai souks constitute a rare example of living heritage in the Gulf, vital today as in the past, that still bring a relevant share of income to Dubai commercial balance. While the overall economic system has evolved, and Dubai has now acquired a global relevance, the original core of the settlement-with its commercial organisation based upon the complementary roles of rulers, merchants, and shipmen from different countries-has been preserved. Dubai's historic centre is a lively urban sector and an active economic entity based upon the free trade principles established by Dubai Rulers at the beginning of the $20^{\text {th }}$ century. The vitality and multiplicity of Dubai heritage is exemplified by the many wooden dhows that continue entering the creek to moor, load, and unload their goods, carrying every year thousands of tons of goods and manufactured products across the Gulf and to the African and Indians coasts. 


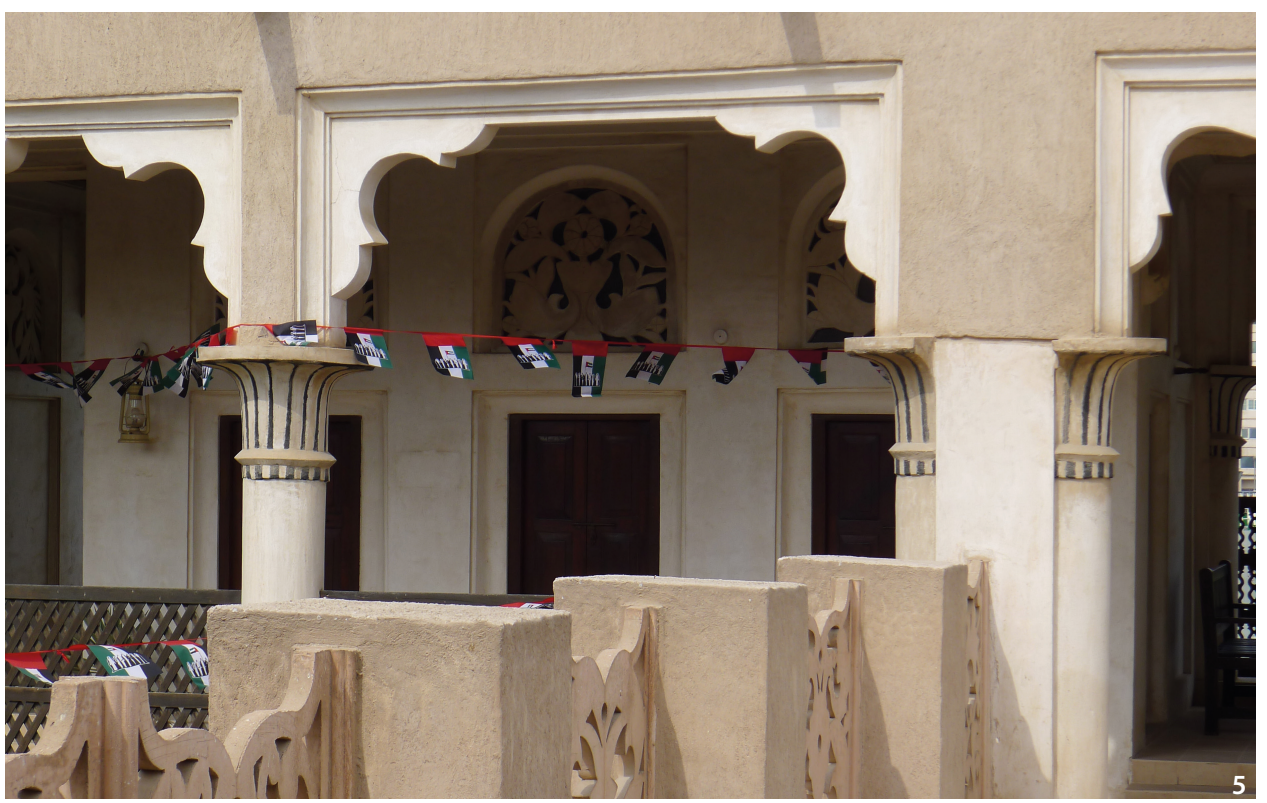

Figure 5 Celebrating National Day in a restored House, 2012 (Source: the author).

In the context of the Gulf, it is also important to underline that Dubai-originally a sea-oriented settlement attracting a religiously and ethnically diverse populationhas shown, and continues to show, a remarkable degree of religious openness. Not only modern churches and a large Sikh temple have been built in the modern city (on land offered by the Ruler), but also the historic sector of the city boasts the only active Hindu temple in the Arabian Peninsula. The presence of long-established foreign communities of traders in the city centre, with their own religious facilities (Al Sayegh 1998), is a powerful reminder of the complexity and multiplicity of the Gulf societies and of their multi-layered heritage.

\section{Conservation, Identity and Tourism}

Since the beginning of the conservation and restoration projects, Dubai Municipality has paid a great attention to the development of outreach activities to raise Dubai residents' awareness of the city's cultural heritage, in the framework of an overall campaign to strengthen the sense of belonging in the young generations. Dubai's approach to heritage conservation is intimately connected to the desire of reinforcing the 'national identity' of the Emirati citizens, a particularly relevant issue in Dubai where only some $10 \%$ of the population is Emirati and where the young citizens have never known the world their parents and grandparents used to live in (Figure 5). But Dubai heritage has also been used as an opportunity of integration for the non-Emirati residents of the city, through the presentation of Dubai's traditions and culture to foreign residents. Reconstructing heritage buildings and neighbourhoods in Dubai acquires therefore meanings that challenge many pre-conceived ideas about this controversial practice. Heritage reconstruction in the Gulf is the result of a reaction to the too rapid and all-encompassing changes of the urban and social environment produced by the oil 'boom', and might be considered as the expression of the strong aspiration of the population to reconnect with their roots and identity (Aslan and Assi 2016). Shindagha neighbourhood reconstruction aims to preserving a deeply felt collective memory in the midst of unprecedented demographic movement, landscape transformation, and technological changes. As reminded by Neil Asherman, ‘... reconstructed heritage structures based on careful research, documentation and traditional building techniques can become sites where contemporary communities can be encouraged to maintain and transmit the particular forms of tangible and intangible heritage to younger generations...' (Aslan and Assi 2016, 45). Furthermore, the low-rise volumes of the reconstructed quarter along the creek have an evident positive impact on the urban landscape of the city centre, and participate to the tourism and business-oriented plans designed by the Emirate of Dubai. The preservation and re-creation of a large historic urban centre gives Dubai a unique position in the Gulf context: while Doha or Abu Dhabi have invested in modern museums and cultural institutions designed by world-famous architects, Dubai has been able to capitalise on its own specific urban heritage to attract high-end visitors.

In a city undergoing a continuous transformation like Dubai, however, also the policies and strategies 


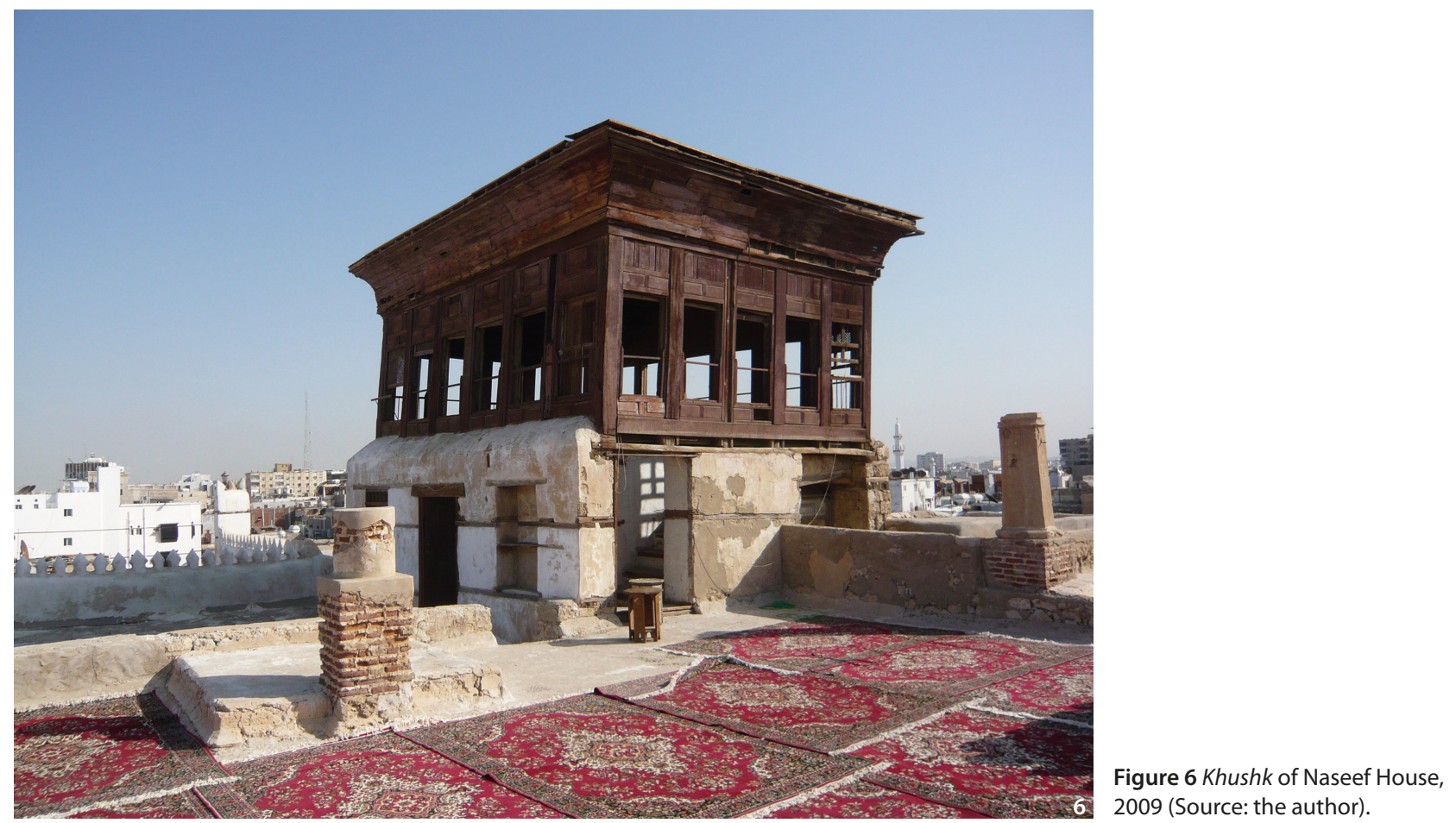

concerning heritage might rapidly evolve. The preservation of the rich and multiple heritage of Dubai is not a once for all 'given', but is continuously threatened by the dynamics active in the larger metropolis, where new ideas and new plans are continuously put forth in a city that endlessly re-invents itself. The eventual inscription of Khor Dubai on the World Heritage List in the coming years might be instrumental in preserving the quality of the site and in maintaining and reinforcing its traditional economics dynamics and heritage significance.

\section{Dubai and the Historic Urban Landscape (HUL) Approach}

Dubai Municipality heritage strategy promotes the traditional commercial life and cultural openness of historic Dubai. Building upon the complete inventory of the historic properties carried out by the Architectural Heritage and Antiquities Department, UNESCO World Heritage nomination aimed at preserving and enhancing the traditional creek harbour and its surrounding historic souks and residential areas on the assumption that the modern city finds its raison d'être in the creek and needs to keep its connection with the past to imagine the future. The preservation of the very identity of the city is perceived as fully compatible with the natural evolution of an extremely dynamic urban environment that finds the origin of its entrepreneurship and financial vitality in the political and economic principles and living traditions that have permitted its unique development since the end of the $19^{\text {th }}$ century. The project-echoing the principles of the 2011 UNESCO HUL Recommendation-involved the local stakeholders, took into consideration the relevance of the geographic and historic setting, and designed a development strategy integrating heritage values into the wider development framework.

\section{Jeddah}

\section{The Historic City and Its Evolution}

Located on the eastern coast of the Red Sea, Jeddah is the second largest city in the Kingdom of Saudi Arabia. The origins and early evolution of the city are relatively little known, and modern archaeological and scientific research on the city is still largely to be done.

In 647, following the advent of Islam, Jeddah was designated as the gateway port for pilgrims travelling to the Holy Cities of Makkah and Madinah by sea. Since, hundreds of thousands of people of diverse nationalities and cultures have been passing through the city. Some of these pilgrims and merchants remained and settled down, laying the foundation for today's cosmopolitan metropolis.

There are no standing buildings from the early Islamic period in Jeddah, and the most important pre- $19^{\text {th }}$ century building, al-Shafi Mosque, dates from the $16^{\text {th }}$ century (King 1998). The historic city developed for centuries within its $16^{\text {th }}$ century protective walls, and only in 

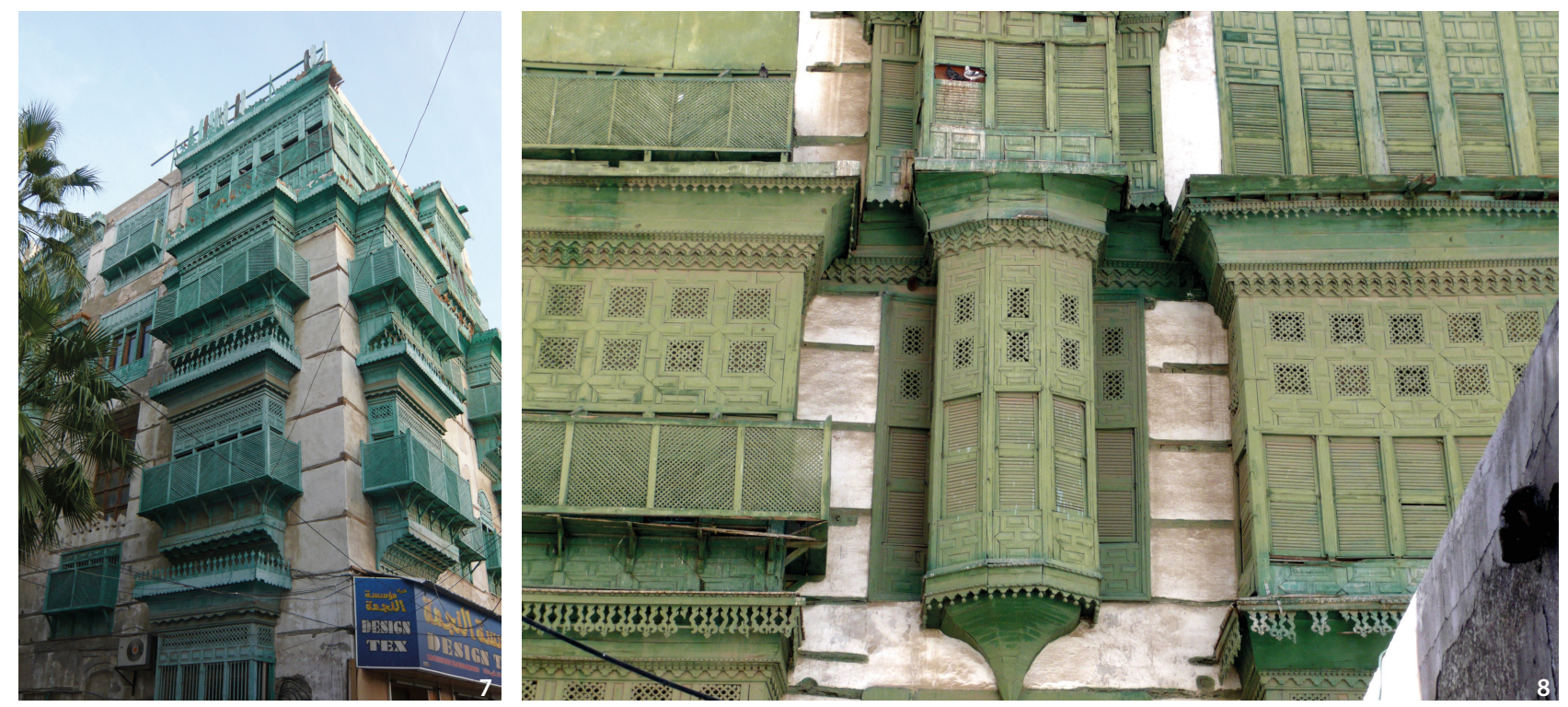

Figure 7 Shafey House, 2009 (Source: the author).

Figure 8 Roshan of Noorwali House, 2009 (Source: the author).

the second half of the $20^{\text {th }}$ century, with the stabilisation of the political situation and the progressive inflow of oil revenues, Jeddah began developing outside the walls that were demolished in 1947 (Pesce 1974).

The residential fabric of the historic city presents specific characteristics setting it apart from most traditional Arab cities. Historic Jeddah is characterised by a high and compact urban typology where houses-isolated or aggregated in blocks surrounded by roads on all four sidesacquire a unique status and establish a direct relationship with the road in front of them (Cuneo 1978). Family and social life takes place both on the high roofs of the palaces and within a set of complex and diversified urban spaces including, besides the traditional souks and mosques, also public squares where develops a rich and multiple social interaction (Figure 6). Most of the structures making up this dense urban fabric are less than 200 years old. The urban layout of the city, and the very architectural style of Jeddah's buildings however, if not the buildings themselves, are much older and probably date at least to the $16^{\text {th }}$ century (Kingdom of Saudi Arabia 2013, 48-51).

The tower-house, a mixed-use building typology sharing residential and commercial activities typical of Jeddah, emerged following the opening of the Suez Canal in 1869, when the leading merchants families built elaborately decorated houses reflecting their new position and wealth. Flourishing trade also favoured the importation of hardwood, primarily from Asia, thus increasing the quality and quantity of wood used in construction and façade treatments (Figure 7). This unique architectural style typical of the Red Sea cities, resulting from the economic and cultural exchanges between Asia, Africa and the Arabian Peninsula throughout the centuries, can now be found almost exclusively in Jeddah, because 'of the more than a dozen ports that have served merchants, pilgrims and navies along the long Red Sea route linking Asia and Europe, Jeddah is the city that has best withstood the test of time. Its city centre still contains multi-storey houses of coral stone and plaster adorned with teak doorways and latticework balconies that symbolised the architecture in ports on both sides of the Red Sea until the $19^{\text {th }}$ century' (Facey 2005, 1) (Figure 8).

Until the early 1950s, extended Saudi families and longestablished Yemeni, Indian and East Asia trading families inhabited the houses of the old city. Following Jeddah's spectacular growth, stimulated by increasing oil revenues, local residents left their traditional dwellings to move to the newly built suburbs (Bokhari 1983). The old city houses are now mainly over-occupied by a high proportion of single, male foreign workers renting rooms from Saudi landlords and supplying the labour for the city's economy. Many of these workers are non-Arabs from East and South-West Asia and from Africa. Their social and economic conditions are often precarious and many residents are illegal aliens that cannot find regular works and live of meagre resources and mean jobs.

After 1947, modern Jeddah grew rapidly and by 1956 it already covered over 3,300 ha (10 times more than the Old City). By 1971, Jeddah counted 350,000 inhabitants with residential neighbourhoods extending mostly to the 


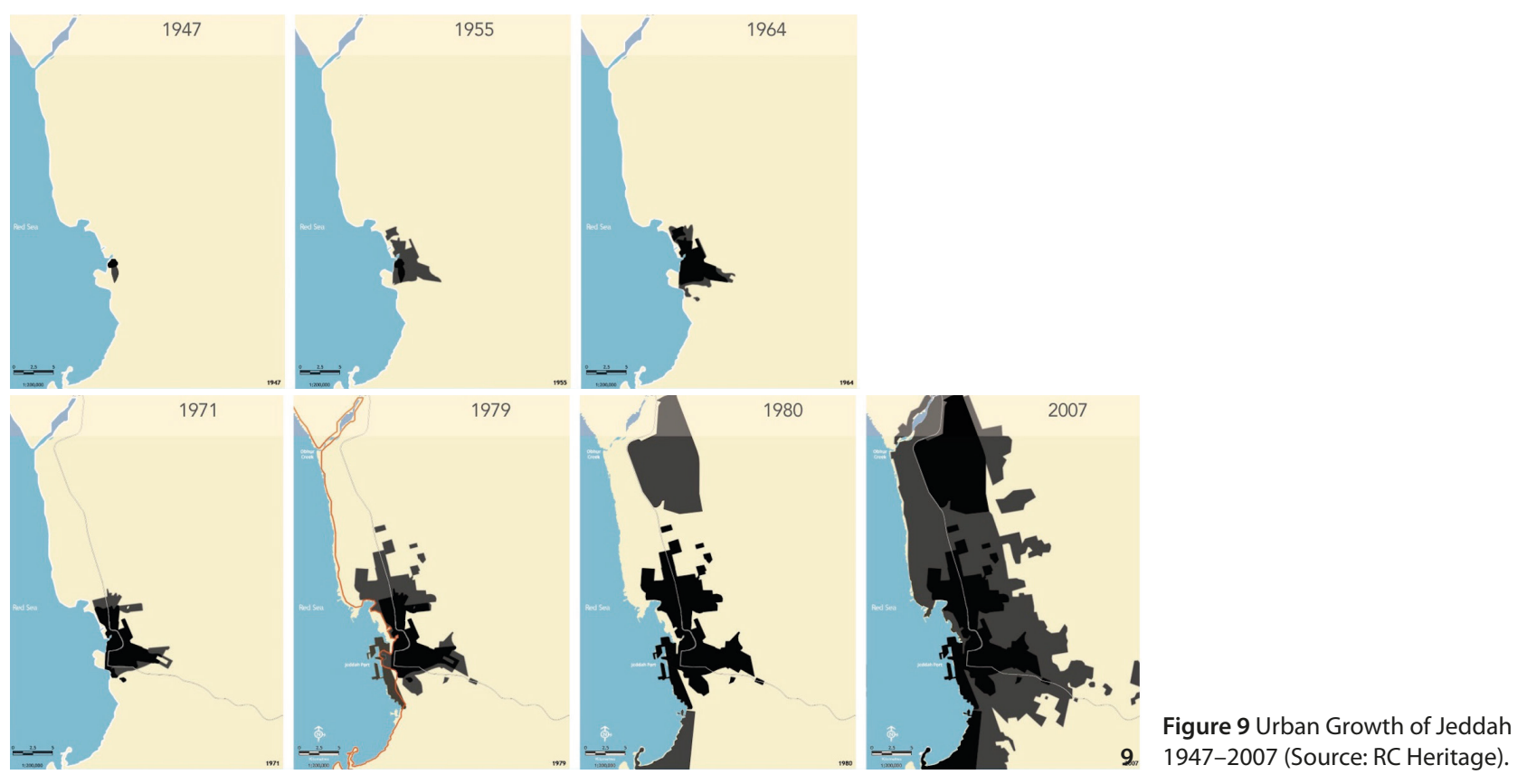

north. The 1973 Oil Crisis paved the way for the constructive 'boom' that transformed completely the city. By the end of 1970 s, Jeddah reached 1 million inhabitants. In 1976, the Islamic Port was created on reclaimed land in front of the Old City. The port transformed the coastline and cut the historic relationship between the Old City and the sea dramatically altering the urban structure of the historic centre. In the period 1980-2010, the city continued its expansion to cover almost $1,000 \mathrm{~km}^{2}$. In some 50 years the city multiplied by 100 the number of its residents, passing from 35,000 in 1947 to 3,500,000 people in 2000 (Abdu, Salagoor and Al-Harigi 2002) (Figure 9).

\section{0s Conservation Plans and Issues at Stake}

Until the 1960s, the skyline of Jeddah was still dominated by the minarets of its mosques and by the high houses of the merchants. Today, the remaining mosques and merchants' houses of Old Jeddah are mostly concealed behind the modern skyscrapers of the business district as large part of its historical and architectural heritage was swept away in the 1960s and 1970s (Christie 1987).

In 1979, when the pace of expansion began to slow down, a British consulting firm made the first detailed study of Old Jeddah and drew up plans to preserve the area's unique architecture (Matthew 1980). The plans called for the old city to remain a residential area and the seat of commercial enterprises, and emphasis was placed on the treatment of public spaces. The 1980s first preservation strategy permitted to slow down the pace of destruction and to launch some conservation project in the Old City, but wasn't able to modify the economic dynamics of the city. In the past 30 years, the number of traditional houses in the old city has continued to decrease (from about 1,000 to 300), and the remaining historic houses are often in poor static conditions and on the verge of collapse.

In the period 2006-2010, a new strategy, based upon the acknowledgement of the role of the private sector and on the full integration of economic and financial considerations in the conservation strategy, was developed for the Old City of Jeddah. Pursuing World Heritage status was perceived as a key element for the success of the overall plan that attempted to overcome the obstacles that led to the partial failure of the previous efforts. The general scheme was based on the concept of 'exchange of property rights' for land and property owners of the Old City. In order to 'accept' new binding preservation regulations within the historic sector, owners were granted privileged regulations in other zones of the modern metropolis. The breaking out of the international financial crisis in 2008, and the difficulties that appeared in defining the respective roles of private and public sectors, however, led to the premature shelving of this private-driven urban conservation strategy.

Plans aiming at a defining a development strategy involving both the historic core and the modern metropolis should be based upon an inclusive assessment of the specific issues at stake in the city of Jeddah. While Historic Jeddah shares many similarities with other historic Arab city centres that struggle for their survival, and notably faces: 
- The abandonment of the city centre by its bourgeoisie, that moved outside the old cities to resettle in modern and richer suburbs, and its replacement by a new, poorer population;

- Complex ownership issues related to Islamic inheritance system;

- The presence of properties belonging to the Islamic awqaf administration (that generally lacks both the financial and the technical means to guarantee their maintenance and preservation);

- The transformation of its still active economic centre into a low-price souk with most ground floors used for retail shops and storage and with the upper levels left empty and rapidly decaying;

- Investments and modernisation concentrating on modern areas, largely bypassing the historic core;

- The almost complete loss of emotional and cultural connection between modern residents and the city's heritage and traditional building know-how;

- The absence of urban heritage protection laws and bylaws that permitted the erasure of most of the historic fabric and architecture of the Old City and its replacement with modern construction (sometimes of high quality), as the Old City was actually included in the urban development plans that have created the modern metropolis.

It also shows unique characteristics that set Jeddah apart from the other Arab historic cities, and that might offer the key for achieving a successful urban revitalisation plan. These unique characteristics include:

- The considerable financial means and technical knowhow of the Kingdom of Saudi Arabia that could be used for the revitalisation of the Old City;

- The enormous appeal of Jeddah, as gate to Makkah, for millions of Muslims worldwide that can act as a magnet capable to attract funds for a modern sustainable development;

- The origins of newcomers settling in the Old City who are not coming from the countryside, like in most Arab historic cities, but are mainly poor citizens of Muslim countries often arriving as pilgrims for the hajj and remaining in the Kingdom without regular immigration visas;

- The relatively minor role played by the state and the public sector in the Kingdom of Saudi Arabia and the prevalence of the private sector as driving economic force;

- The capacity of Jeddah historic landowners to invest large amount of money in the city and to contribute to new sustainable urban conservation policies.

\section{New Conservation and Development Plans}

\section{After 2010}

World Heritage and the Revitalisation of the Old City In the past years, an innovative vision-placing heritage, identity and tourism at the centre stage of developmenthas led to a profound modification in the approach to the old city. Since the early 2000s, for the first time, Historic Jeddah has been included in the overall economic strategic thinking for the future of the metropolis and of the Kingdom of Saudi Arabia. While earlier conservation strategies aimed at 'preserving' heritage as a memory of the past, setting it apart from urban development, the new plans aim at including heritage in the urban and economic dynamics. The current strategy for the revitalisation and preservation of the Old City focuses on public-driven initiatives that are meant set up a virtuous circle capable to preserve and revitalise the ensemble of the Old City of Jeddah. It is considered that once a 'new start' is made, the Old City has the capacity to attract private investments not only as a tourist area, but also as a commercial sector (with its many important private companies and its souks attracting millions of customers from all social groups). The new vision tackles the revitalisation of historic Jeddah at different levels, involving a large number of stakeholders among which Jeddah Chamber of Commerce, Old City Owners' Associations and local NGOs. For the first time, also the awaqf, the administration of religious Islamic endowments, is actively participating to the revitalisation process.

The new urban conservation and revitalisation plan is based upon a complete inventory of the Old City, including an assessment of the static conditions of the historic buildings, and upon a new set of urban regulations elaborated within the World Heritage Nomination process (Figure 10). In this context, conservation-related issues are of paramount importance, and in 2012 an external specialised Saudi company was contracted by the Municipality to provide technical support in architectural conservation (Kingdom of Saudi Arabia 2013).

In the meantime, Jeddah Municipality is also working at the larger metropolitan scale with the preparation of a new Master Plan for the entire urban area. One of the priorities of the plan is the re-organisation of mobility within the city and the creation of a public transportation multimodal network. An international team, that includes Sir Norman Foster's firm, has designed four lines of metropolitan trains and a new system of busses and trams to reduce the number of cars and to limit and control car circulation also within the Old City. Unfortunately, however, 

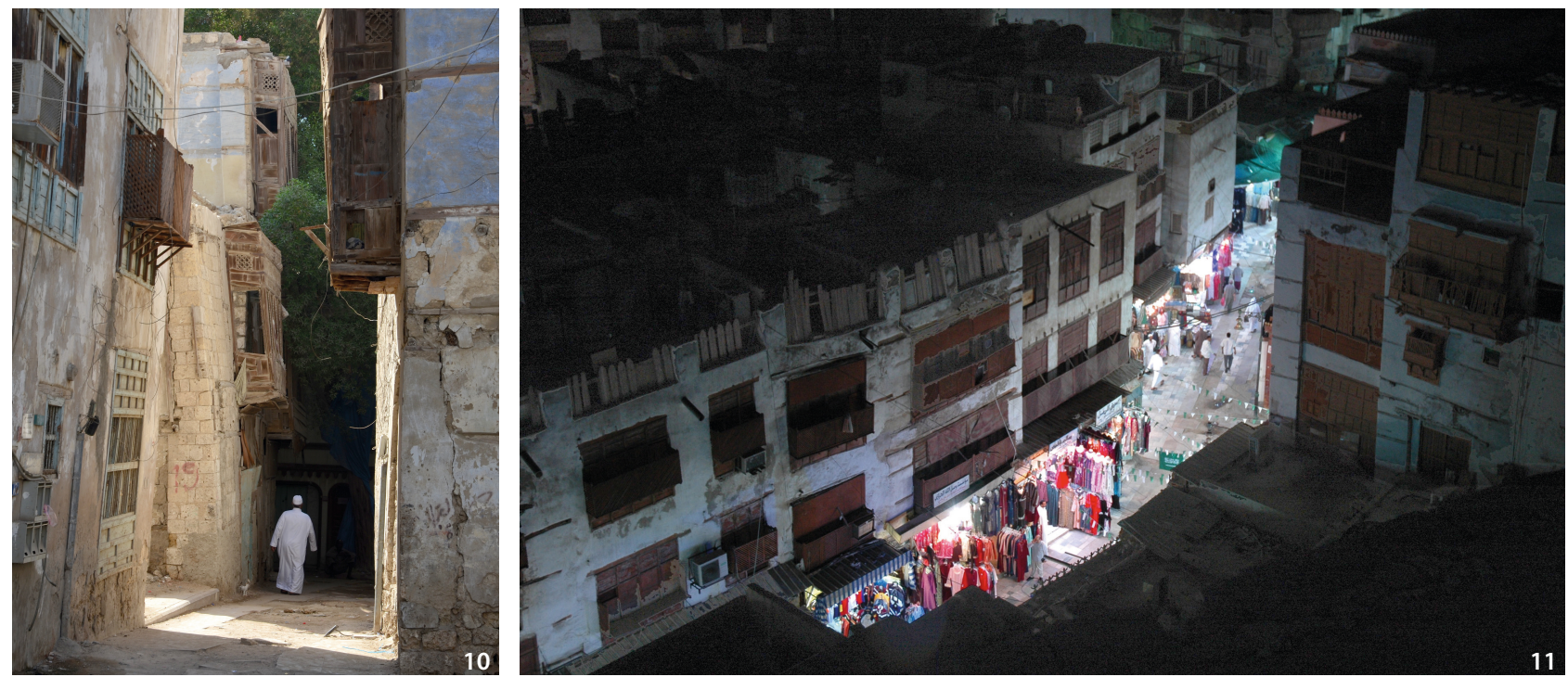

Figure 10 Decaying historic houses, 2012 (Source: F. Cristofoli).

Figure 11 Old city souk by night, 2007 (Source: C. Graz).

this major project has been halted in 2016 and it is not clear at the moment if, and when, it might resume.

\section{Administrative and Legal Framework}

Two recently approved legal tools permit the implementation of the program:

- The new Law on Antiquities, Museums and Urban Heritage (approved in 2014) that gives the Saudi Commission for Tourism and National Heritage (SCTH) the power to deal with urban heritage, paving the way for the formal protection of historic neighbourhoods across the Kingdom;

- The new municipal building regulation based upon the Guidelines developed in the framework of the preparation of the World Heritage Nomination prepared by an international engineering consulting company contracted by Jeddah Municipality.

The management system designed to preserve and revitalise the Old City is supported by a system of higher institutions and committees to favour the effective participation of the ensemble of the stakeholders, both at the local level inside the Old City and at the higher governorate and national levels. The strong financial commitment and support of the Saudi Government, which allocates an important and regular flow of resources for the realisation of the preservation and development plans of the historic city, make the implementation of this mechanism possible. Besides, a credit programme, resulting from an agreement between SCTH and a governmental bank, has also been created. The scheme, supported by a Royal Decree, states that every owner who wants to restore his historic house can receive a loan without interest from the government if he presents a plan proposing the reuse of the structure for cultural-tourism activities (Kingdom of Saudi Arabia 2013).

\section{An Assessment of the Revitalisation Plans}

\section{A Long-term Planning Approach: The 2010 Master Plan}

In 2010, the British firm Happold Consulting designed for Jeddah Municipality the overall framework directing the interventions in the old city of Jeddah. The Jeddah Strategic Plan 2010-2030 identified four main axes for the revitalisation of the Old City of Jeddah:

- Embrace Jeddah's role as the gateway to Makkah and Madinah;

- Develop Jeddah's role as an international meeting place for people from all over the Islamic World;

- Develop strong, integrated and supportive communities and neighbourhoods where Jeddah's collective identity is fostered and its diversity is celebrated, to make Jeddah again a significant meeting place and cultural centre for the Islamic World;

- Recognise the value of Jeddah's historic buildings, places, monuments and traditions and preserving them for future generations.

Throughout the past years, local authorities have been following this global strategy and have acted to materialise these concepts into actual facts on the ground. The World Heritage inscription of Historic Jeddah, the Gate to Makkah has been a key element of this overall strategy, instrumental for its overall success. 


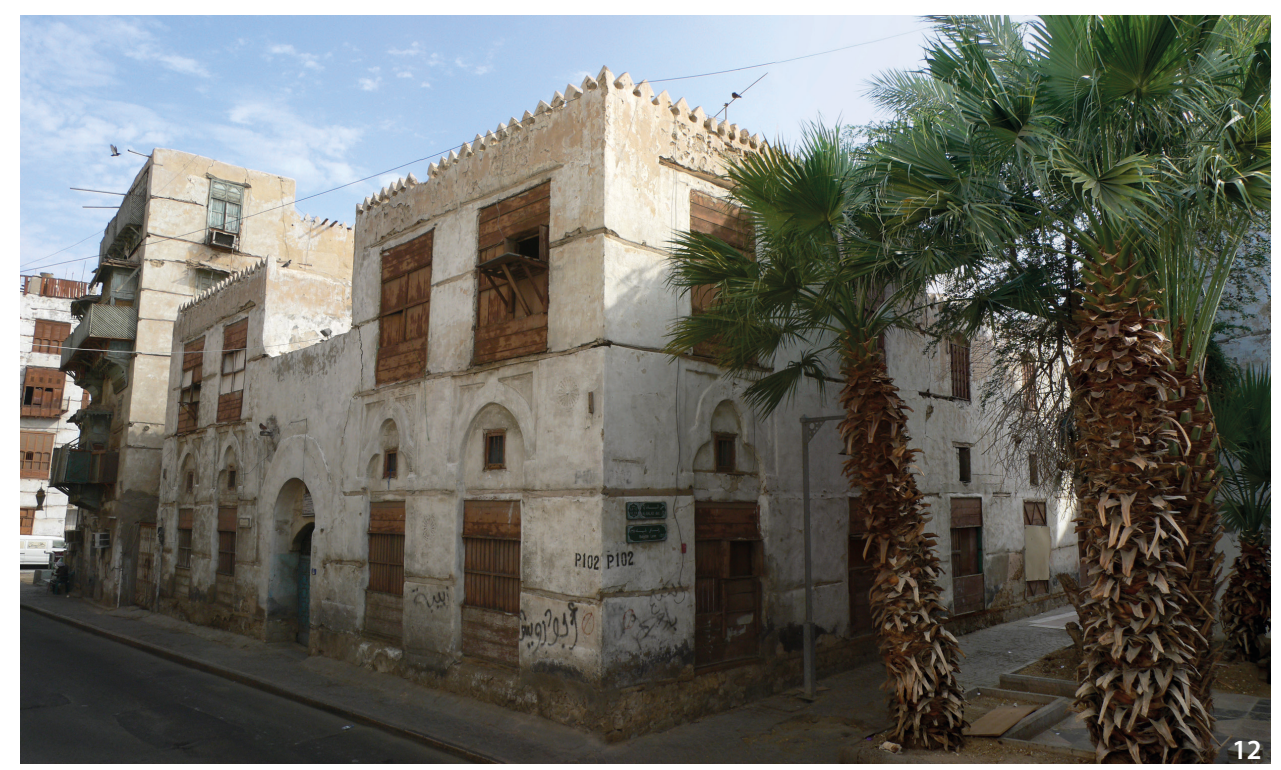

Figure 12 Historic caravanserai, 2009 (Source: F. Cristofoli).

\section{Conservation, Civil Society and Tourism in Jeddah} In the past five years, local community and Islamic religious charities have carried out a series of bottom-up activities to supplement top-down public sector initiatives. The active presence of the civil society in Historic Jeddah revitalisation process marks a new phase in the social and cultural life of Saudi Arabia. Local associations, and independent initiatives by university professors and intellectuals, have contributed to the promotion of the site and to re-creating the bond between the historic city and the residents of modern Jeddah (Figure 11). In the very specific Saudi Arabian context, social media and Internet have been instrumental in developing these associations and in connecting Saudi men and women interested in the preservation and revitalisation of their heritage (Montagu 2015). These associations have worked hand in hand with religious charities and have realised an impressive number of raising awareness initiatives and social programs to upgrade the living conditions of the residents of the Old City.

In 2014, the Historic Jeddah Festival was established attracting in just ten days some 750,000 people, mostly from Jeddah, to the Old City. This event represented the largest cultural and tourism initiative ever launched in Jeddah and is a significant milestone in the on-going revitalisation process of the historic city centre. The second edition of the festival, in 2015, met with similar success. These festivals have underlined the role of Jeddah as source of culture, literature and history, and are positively reflecting on the performance of businesses in Jeddah, offering a glimpse on the long-term potential of the site for the economy of the city. These initiatives have strongly contributed to the creation of new emotional bonds between
Jeddah residents and their heritage, a result that couldn't be achieved by the earlier attempts of the 1980s.

The revitalisation plan being implemented the Old City of Jeddah aims at making the Old City once again the vibrant heart of the modern metropolis. The development of suitable facilities to receive tourists is one of the main elements of the plans being developed jointly by the Municipality of Jeddah and the private sector. Until now, tourism in the Kingdom of Saudi Arabia is principally targeting Saudi nationals and Muslims from the Gulf Region and beyond, and is connected to the development of tourism 'packages' for pilgrims arriving in Saudi Arabia to perform umra. But the government has the ambition to develop also different forms of tourism, including conference and event tourism, and leisure tourism. Jeddah, the main urban centre on the Red Sea coast and a major regional commercial hub, is meant to play a pioneering role in this strategy (Figure 12).

\section{Conclusion}

The plans implemented in the past 10 years in Dubai and Jeddah show that the region has entered a new historic phase characterised by the concern for the preservation and development of urban heritage that is now considered both as an economic resource and an identity-making tool. The favourable economic situation of the region, and the activities of highly qualified international planning companies, have resulted in the definition of innovative conservation and revitalisation strategies that aim to integrate advanced theoretical heritage frameworks into an urban landscape generally perceived 
as entirely modern and drastically refusing its original built fabric.

The urban conservation plans of Dubai and Jeddah demonstrate the catalysing role played by the 1972 World Heritage Convention and the relevance of contemporary international approaches to urban revitalisation and development in the Arabian context. What takes place in these cities since 2010 is an important breakthrough, and shows how international best practices can be creatively adapted to the specificities of the Arabian Peninsula context. Indeed, even though it might be argued that:

- Urban revitalisation strategies based on the injection of public funds to trigger 'virtuous circles' leading to the urban regeneration of decayed city centres-like the one proposed in Jeddah have been applied in other cities worldwide and have not always been successful;

- The association of state funds and private capitals might pave the way to abuses, and to the gentrification of historic centres instead of improving the living conditions of the residents;

- And, the focus on cultural tourism-that in different forms underpins both Jeddah and Dubai historic centres plans-is an almost standard solution for the revitalisation of historic cities across the world often producing in return standardised urban 'historic' environments and simplistic profit-driven solutions,

It should be unambiguously underlined that the policies implemented in these two historic cores have already had long-lasting positive results and mark an entirely new phase for the Arabian Peninsula:

- In Dubai, the integration of tangible and intangible heritage elements, the perception of the specificity of local identity versus a globalised standard 'modernity', and the study and preservation of traditional building know-hows, contribute to the definition of a more sustainable future for a metropolis known for its excesses and out-of-scale grandiose plans.

- In Jeddah-notwithstanding the complexity of the ownership pattern, the value of the land and the speculative pressures on the Old City-heritage-centred policies have permitted to reconnect modern Saudi citizens with their roots, recreating a sense of belonging and pride in the city's history and heritage.

The strategies designed by Saudi authorities and by Dubai Municipality for their urban historic cores build upon the uniqueness of the culture and heritage of these two cities, acknowledging their role as engines for development, and their relevance for the future of the modern metropolises. These urban development strategies follow the principles underpinning the Historic Urban Landscape approach-aiming 'at preserving the quality of the human environment, enhancing the productive and sustainable use of urban spaces while recognising their dynamic character, and promoting social and functional diversity integrat(ing) the goals of urban heritage conservation and those of social and economic development' 'while respecting the values of the national and international communities' (UNESCO 2011, art. 11,13)-providing an important, though relatively little known, reference for planners and researchers around the globe.

Even though never directly referred to in the planning documents of the two cities-and never used as a reference for the building up of the World Heritage nominations files-the HUL Recommendation is the underlying theoretical framework driving the recent development of these two cities. Jeddah and Dubai perfectly epitomise the extremely dynamic urban environments where the conservation of built heritage is subject to particularly difficult compromises and adaptations for which the HUL approach has been conceived. Therefore, the HUL approach innovative operational principles, positioning the historic city as a resource for the future, have been-more or less consciously-followed by the cities authorities that have notably respected the 'Six Steps' outlined by Bandarin and van Oers (2012).

While until recently the Gulf urban development process was dominated by a conceptual framework based on engineer-driven plans modifying the natural landscape to adapt it to human needs, and by major land reclamations and out-of-scale infrastructure projects (highways, artificial islands and deep-water harbours), Jeddah and Dubai prove that a radical evolution is now taking place and that heritage and culture are contributing to the creation of a new vision for the Gulf cities of the $21^{\text {st }}$ century.

The urban policies and heritage-focused strategies developed by Dubai and Jeddah represent a major conceptual breakthrough not only in the Gulf, but also at the global scale, and the strategies briefly outlined in this article provide elements of reflection and comparison that can be relevant for other urban environment, and notably for the rapidly developing Asian and Chinese metropolises.

\section{References}

Abdu, Mohamed Sani, Jalaluddin Yousef Salagoor, and Fahad An-Nwisser Al-Harigi. 2002. "Jeddah Urban Growth and Development process: the Underlying Factors." Scientific Journal of King Faisal University 3 (1): 111-135. 
Al Sayegh, Fatima. 1998. "Merchants' Role in a Changing Society: the Case of Dubai 1900-1990." Middle Eastern Studies 34 (1): 87-102.

Aslan, Zaki, and Eman Assi. 2016. Urban Conservation and Reconstruction in the Gulf. Dubai: Dubai Municipality.

Assi, Eman. 2015. "Urban Conservation and Reconstruction in the Gulf: The Case of Dubai." Sustainable Development, Culture, Traditions 1a. Accessed 17 September 2018. http://sdct-journal.com/index.php/2015-10-1822-23-19/2015-volume-1-a/376-urban-conservationand-reconstruction-in-the-gulf-region-the-case-ofdubai

Assi, Eman, and Rashad Bukhash. 2011. Traditional Houses of Dubai. Dubai: Municipality of Dubai.

Bandarin, Francesco, and Ron van Oers. 2012. The Historic Urban Landscape: Managing Heritage in an Urban Century. UK: Wiley-Backwell.

Bokhari, Abdulla Y. 1983. "Conservation in the Historic District of Jeddah." In Adaptive Reuse: Integrating Traditional Areas into the Modern Urban Fabric, edited by Margaret Bentley Sevcenko. Cambridge, Mass: MIT Laboratory of Architecture and Planning.

Boussaa, Djamel. 2014. "Cultural Heritage in the Gulf: Blight or Blessing? A Discussion of Evidence from Dubai, Jeddah and Doha." Middle East - Topics \& Arguments 3: 55-70.

Christie, John. 1987. "A City within a City." Saudi ARAMCO World 38 (5).

Coles, Anne, and Peter Jackson. 2007. Windtower: Houses of the Bastaki. London: Stacey International.

Cuneo, Paolo.1978. "The Cities of the Red Sea." [Le città del Mar Rosso.] Storia della città 7:26-42.

Damluji, Salma Samer. 2006. The Architecture of the United Arab Emirates. Reading: Garnet Publishing.

Facey, William. 2005. "Queen of the India Trade." Saudi ARAMCO World. 56 (6): 10-16.

Heard-Bey, Frauke. 2004. From Trucial States to the United Arab Emirates, A Society in Transition. Dubai: Motivate Publishing.

Helmy, Mona. 2008. "Urban Branding Strategies and the Emerging Arab Cityscape. The Image of the Gulf City." PhD Diss., Universität Stuttgart, Städtebau-Institut.

King, Geoffrey. 1998. The Traditional Architecture of Saudi Arabia. London: I.B. Tauris.

Kingdom of Saudi Arabia. 2013. "Historic Jeddah, the Gate to Makkah. Nomination File for Inscription on the UNESCO World Heritage List." Accessed 17 September 2018. http:// whc.unesco.org/en/list/1361/?documents=1\&
Matthew, Robert. 1980. Jeddah: Historic Area Study, Design Demonstration Study. Minister of Municipal and Rural Affairs. Jeddah: Municipality of Jeddah.

Montagu, Caroline. 2015. "Civil Society in Saudi Arabia: The Power and Challenges of Association." Research Paper, Middle East and North Africa Programme, Chatham House, UK.

Olroyd-Robinson, Keith. 2006. "The Urban Architecture of Bastakiyyah." In The Architecture of the United Arab Emirates, edited by Salma Damluji, 179-204. Reading: Garnet Publishing.

Pacione, Michael. 2005. "City Profile: Dubai." Cities 22 (3): 255-265.

Pesce, Angelo. 1974. Jiddah, Portrait of an Arabian City. London: Falcon Press.

Rab, Samia. 2010. "Dubai: Architecture and Heritage in Service of Globalisation”. In Espaces urbains à l'aube du XXI $I^{\text {me }}$ siècle, Patrimoine et héritages culturels, edited by Philippe Boulanger and Céline Hullo-Pouyat, 221-229. Paris: PUPS.

UNESCO. 2011. Recommendation on the Historic Urban Landscape. UNESCO. Accessed 17 September 2018. https://whc.unesco.org/uploads/activities/documents/ activity-638-98.pdf

United Arab Emirates. 2012. "Khor Dubai. Tentative List for UNESCO.” Accessed 17 September 2018. http:// whc.unesco.org/en/tentativelists/5662/

Wheeler, Julia, and Paul Thuysbaert. 2005. Telling Tales, an Oral History of Dubai. Dubai: Explorer Publishing.

Wirth, Erich. 1988. "Dubai. A Modern Urban Trading and Service Center on the Arabian-Persian Gulf." [Ein modernes städtisches Handels und Dienstleistungszentrum am Arabisch-Persischen Golf.] Erlangen Geographische Arbeiten 48. 